Pacific Journal of Mathematics

AN ERGODIC PROPERTY OF LOCALLY COMPACT

JABS CHIN-SZE WONG 


\title{
AN ERGODIC PROPERTY OF LOCALLY COMPACT AMENABLE SEMIGROUPS
}

\author{
JAMES C. S. WONG
}

\begin{abstract}
Let $M(S)$ be the Banach algebra of all bounded regular Borel measures on a locally compact semigroup $S$ with variation norm and convolution as multiplication and $M_{0}(S)$ the probability measures in $M(S)$. We obtain necessary and sufficient conditions for the semigroup $S$ to have the (ergodic) property that for each $\nu \in M(S),|\nu(S)|=\inf \left\{\|\nu * \mu\|: \mu \in M_{0}(S)\right\}$, an extension of a known result for locally compact groups.
\end{abstract}

1. Notations and terminologies. We shall follow Hewitt and Ross [9] for basic notations and terminologies concerning integration on locally compact spaces. Let $S$ be a locally compact semigroup with jointly continuous multiplication and $M(S)$ the Banach algebra of all bounded regular Borel measures on $S$ with total variation norm and convolution $\mu * \nu, \mu, \nu \in M(S)$ as multiplication where

$$
\int f d \mu * \nu=\iint f(x y) d \mu(x) d \nu^{\prime}(y)=\iint f(x y) d \nu(y) d \mu(x)
$$

for $f \in C_{0}(S)$ the space of all continuous functions on $S$ which vanish at infinity. (See for example [1], [6], or [18].) Let $M_{0}(S)=\{\mu \epsilon$ $M(S): \mu \geqq 0$ and $\|\mu\|=1\}$ be the set of all probability measures in $M(S)$. Consider the continuous dual $M(S)^{*}$ of $M(S)$. Denote by 1 the element in $M(S)^{*}$ such that $1(\mu)=\int d \mu=\mu(S), \mu \in M(S)$. Clearly $\|1\|=1$.

2. Convolution of functionals and measures, means. Let $F \in$ $M(S)^{*}, \mu \in M(S)$, we define a linear functional $l_{\mu} F=\mu \odot F$ on $M(S)$ by $\mu \odot F(\nu)=F(\mu * \nu), \nu \in M(S)$. Clearly $\mu \odot F \in M(S)^{*}$. In fact $\|\mu \odot F\| \leqq\|\mu\| \cdot\|F\|$. Similarly we define $F \odot \mu=r_{\mu} F$.

A linear functional $M \in M(S)^{* *}$ is called a mean if $M(F) \geqq 0$ if $F \geqq 0$ and $M(1)=1$. Here $F \geqq 0$ means $F(\mu) \geqq 0$ for all $\mu \geqq 0$ in $M(S)$. An equivalent definition is

$$
\inf \left\{F(\mu): \mu \in M_{0}(S)\right\} \leqq M(F) \leqq \sup \left\{F(\mu): \mu \in M_{0}(S)\right\}
$$

for any $F \in M(S)^{*}$.

Consequently $\|M\|=M(1)=1$ for any mean $M$ on $M(S)^{*}$. It follows that the set of means is weak* compact and convex. Each probability measure $\mu \in M_{0}(S)$ is a mean if we put $\mu(F)=F(\mu), F \in$ 
$M(S)^{*}$. An application of Hahn-Banach Separation Theorem shows that $M_{0}(S)$ is weak* dense in the set of means on $M(S)^{*}$.

A mean $M$ is topological left invariant if $M(\mu \bullet F)=M(F) \forall \mu \epsilon$ $M_{0}(S)$ and $F \in M(S)^{*}$ (see Greenleaf [7] for the case of locally compact groups).

3. Topological right stationarity and ergodic property. Following Wong [16], we say that $S$ is topological right stationary if for each $F \in M(S)^{*}$, there is a net $\mu_{\alpha} \in M_{0}(S)$ and some scalar $\beta$ such that $F \odot \mu_{\alpha} \rightarrow \beta \cdot 1$ weak* in $M(S)^{*}$.

THEOREM 3.1. Let $S$ be a locally compact semigroup, the following statements are equivalent:

(1) $S$ is topological right stationary.

(2) For each $\nu \in M(S),|\nu(S)|=\inf \left\{\|\nu * \mu\|: \mu \in M_{0}(S)\right\}$.

(3) There is a net $\mu_{\alpha} \in M_{0}(S)$ such that $\left\|\mu * \mu_{\alpha}-\mu_{\alpha}\right\| \rightarrow 0$ for any $\mu \in M_{0}(S)$.

(4) $M(S)^{*}$ has a topological left invariant mean.

\section{Proof.}

(1) implies (2).

Assume that $S$ is topological right stationary, we modify the arguments in Glicksberg [5, Lemma 2.1] to show that $S$ has (ergodic) property (2). Observe that

$$
\|\nu * \mu\|=|\nu * \mu|(S) \geqq|\nu * \mu(S)|=|\nu(S) \mu(S)|=|\nu(S)|
$$

for any $\mu \in M_{0}(S), \nu \in M(S)$. Hence $|\nu(S)| \leqslant \inf \left\{\|\nu * \mu\|: \mu \in M_{0}(S)\right\}$. Now let $c=\inf \left\{\|\nu * \mu\|: \mu \in M_{0}(S)\right\}>0$. By Hahn-Banach Extension Theorem, there is some $F \in M(S)^{*}$ such that $\|F\|=1$ and

$$
c \leqslant|(F, \sigma)| \text { for any } \sigma \in C_{\nu},
$$

the norm closure of the convex set $\left\{\nu * \mu: \mu \in M_{0}(S)\right\}$ in $M(S)$. Let $C_{F}$ be the weak* closure of the convex $\operatorname{set}\left\{F \odot \mu: \mu \in M_{0}(S)\right\}$ in $M(S)^{*}$. Since $(F, \sigma * \mu)=(F \odot \mu, \sigma)$, it follows that

$$
c \leqslant|(G, \sigma)| \quad \forall \sigma \in C_{\nu} \text { and } G \in C_{F} .
$$

But $S$ is topological right stationary, there is some $\beta$ such that $\beta \cdot 1 \in C_{F}$ (here we depart from Glicksberg's proof in [5, Lemma 2.1], see remarks below). Now $\beta \cdot 1$ is constant on $C_{\nu}$ since

$$
\begin{gathered}
(\beta \cdot 1, \nu * \mu)=\beta \cdot(\nu * \mu)(S)=\beta \cdot \nu(S) \cdot \mu(S) \\
=\beta \cdot \nu(S)=(\beta \cdot 1, \nu)
\end{gathered}
$$

for any $\mu \in M_{0}(S)$. Moreover, 


$$
\begin{aligned}
c \leqslant|(\beta \cdot 1, \nu)| & =\inf \left\{|(\beta \cdot 1, \nu * \mu)|: \mu \in M_{0}(S)\right\} \\
& \leqslant|\beta| \cdot \inf \left\{|| \nu * \mu||: \mu \in M_{0}(S)\right\} \\
& =|\beta| \cdot c .
\end{aligned}
$$

Consequently $|\beta|=1$ and $c=|(\beta \cdot 1, \nu)|=|\beta| \cdot|\nu(S)|=|\nu(S)|$.

(2) implies (3).

Except that we work with measures instead of functions this is practically the same as in the locally compact group case (Greenleaf [7, Theorem 3.7.3]). Let $\mu \in M_{0}(S)$ be fixed. Consider the directed system $J=\{\alpha\}$ where $\alpha=\left(\mu_{1}, \mu_{2}, \cdots, \mu_{n} ; \varepsilon\right), \mu_{i} \in M_{0}(S), \varepsilon>0, n$ finite. $\alpha \geqslant \alpha^{\prime}$ means $\left\{\mu_{i}\right\} \supset\left\{\mu_{i}^{\prime}\right\}$ and $\varepsilon \leqslant \varepsilon^{\prime}$. For each $\alpha \in J$, we always have $\left(1, \mu_{i} * \mu-\mu\right)=0 \forall i=1,2, \cdots, n$. By assumption, there exist $\sigma_{1}, \sigma_{2}$, $\cdots, \sigma_{n} \in M_{0}(S)$ such that

$$
\begin{aligned}
& \left\|\left(\mu_{1} * \mu-\mu\right) * \sigma_{1}\right\|<\varepsilon \\
& \left\|\left(\mu_{2} * \mu-\mu\right) * \sigma_{1} * \sigma_{2}\right\|<\varepsilon
\end{aligned}
$$

and

$$
\left\|\left(\mu_{n} * \mu-\mu\right) * \sigma_{1} * \sigma_{2} * \cdots * \sigma_{n}\right\|<\varepsilon .
$$

(Note $(1, \nu)=0$ implies $\left(1, \nu * \sigma_{k}\right)=0$.) Put $\sigma_{\alpha}=\sigma_{1} * \sigma_{2} * \cdots * \sigma_{n}$, then

$$
\begin{aligned}
& \left\|\left(\mu_{k} * \mu-\mu\right) * \sigma_{\alpha}\right\| \\
\leqslant & \left\|\left(\mu_{k} * \mu-\mu\right) * \sigma_{1} * \cdots * \sigma_{k}\right\| \cdot\left\|\sigma_{k+1} * \cdots * \sigma_{n}\right\| \\
= & \left\|\left(\mu_{k} * \mu-\mu\right) * \sigma_{1} * \cdots * \sigma_{k}\right\|<\varepsilon
\end{aligned}
$$

$\forall k=1,2, \cdots, n$. Finally define $\mu_{\alpha}=\mu * \sigma_{\alpha} \in M_{0}(S)$ for $\alpha \in J$. Then $\left\|\nu * \mu_{\alpha}-\mu_{\alpha}\right\| \rightarrow 0$ for any $\nu \in M_{0}(S)$.

(3) implies (4) and (4) implies (1).

These are the same as in the locally compact group case and we omit the details. The reader may consult Greenleaf [7] and Wong [16].

4. Remarks. Equivalence of (2) and (4) is an analogue of a result of $\mathrm{H}$. Reiter on ergodic property of locally compact amenable groups (see Greenleaf [7, Theorem 3.7.3 p. 77]). Equivalence of (1) and (4) is an extension in a slightly different form of a result in Wong [16].

In the proof of [7, Theorem 3.7.3], Greenleaf used Rickert's fixed point theorem [7, Theorem 3.3.1]. If we were to employ the same arguments in proving that (1) implies (2), we would have to invoke an analogous fixed point theorem (see Wong [17, Theorem 3.3] which has a natural extension to locally compact semigroups) for the compact convex set $C_{F}$ (referring to the proof of (1) implies (2)) to produce a 
fixed point $G \in C_{F}$ of norm 1 such that $G \odot \mu=G \forall \mu \in M_{0}(S)$. The question is whether $G=\beta \cdot 1$ for some scalar $\beta$ ? If $S$ is a locally compact group, such a $G$ is necessarily "constant" on $M_{a}(S)=L_{1}(S)$ (the absolutely continuous measures) and, hence on $M(S)$. For general $S$, Greenleaf's proof may not carry over.

Finally, it is easy to see that our definitions are consistent with previous ones given in Greenleaf [7] and Wong [16] for locally compact groups.

5. Continuous functions in $M(S)^{*}$. Let $C B(S)$ be the space of all bounded continuous on $S$ with supremum norm. If $\mu \in M(S)$, $f \in C B(S)$, we can define $l_{\mu} f=\mu \odot f$ and $r_{\mu} f=f \odot \mu($ both in $C B(S)$ again) by putting

$$
\begin{aligned}
& \mu \odot f(s)=\int f(t s) d \mu(t) \\
& f \odot \mu(s)=\int f(s t) d \mu(t), \quad s \in S
\end{aligned}
$$

(see Williamson [15]). Invariant means on $C B(S)$ are defined in the obvious and usual way. Each function $f \in C B(S)$ can be regarded as a functional $T f \in M(S)^{*}$ such that

$$
T f(\mu)=\int f d \mu, \mu \in M(S) .
$$

The map $T: C B(S) \rightarrow M(S)^{*}$ is a linear isometry (into) which commutes with convolution operators $l_{\mu}$ (and also $r_{\mu}$ ). Moreover $T \geqslant 0$ and $T(1)=1$. Therefore, the two definitions of invariant mean on $C B(S)$ and its image under $T$ agree. However, unlike the group case, it is not known if $M(S)^{*}$ has a topological left invariant mean when $C B(S)$ does.

\section{REFERENCES}

1. A. Baker and J. Baker, Algebras of measures on a locally compact semigroup, J. London Math. Soc., (2), 1 (1969), 249-259.

2. M. Day, Amenable semigroups, Illinois J. Math., 1 (1957), 509-544.

3. —_ Fixed-point theorems for compact convex sets, Illinois J. Math., 5 (1961), 585-590.

4. - Correction to my paper "Fixed-point theorems for compact convex sets", Illinois J. Math., 8 (1964), 713.

5. I. Glicksberg, On convex hulls of translates, Pacific J. Math., 13 (1963), 97-113.

6. - Weak compactness and separate continuity, Pacific J. Math., 11 (1961), 205-214.

7. F. P. Greenleaf, Invariant Means on Topological Groups, Van Nostrand Math. Studies 1969.

8. G. Hart, Absolutely continuous measures on semigroups, Dissertation, Kansas State University, Kansas, 1970. 
9. E. Hewitt and K. Ross, Abstract Harmonic Analysis I, Springer-Verlag, 1963.

10. T. Mitchell, Constant functions and left invariant means on semigroups, Trans. Amer. Math. Soc., 119 (1965), 244-261.

11. - Topological semigroups and fixed points, Illinois J. Math., 14 (1970), 630-641.

12. H. Reiter, The convex hull of translates of a function in $L^{1}$, J. London Math. Soc., 35 (1960), 5-16.

13. - On some properties of locally compact groups, Indag. Math., 27 (1965), 687-701.

14. N. Rickert, Amenable groups and groups with the fixed point property, Trans. Amer. Math. Soc., 127 (1967), 211-232.

15. J. Williamson, Harmonic analysis on semigroups, J. London Math. Soc., 42 (1967), $1-41$.

16. James C. S. Wong, Topological stationary locally compact groups and amenability, Trans. Amer. Math. Soc., 144 (1969), 351-363.

17. - Topological left invariant means on locally compact groups and fixed points, Proc. Amer. Math. Soc., 27 (1971), 572-578.

18. - Invariant means on locally compact semigroups, Proc. Amer. Math. Soc., 31 (1972), 39-45.

Received July 17, 1972 and in revised form March 27, 1973. Research supported by NRC of Canada Research Grant No. A8227.

University of Calgary, Canada 



\section{PACIFIC JOURNAL OF MATHEMATICS}

\section{EDITORS}

RICHARD ARENS (Managing Editor)

University of California

Los Angeles, California 90024

\author{
R. A. Beaumont \\ University of Washington \\ Seattle, Washington 98105
}

J. Dugundu*

Department of Mathematics

University of Southern California

Los Angeles, California 90007

D. Gilbarg and J. Milgram

Stanford University

Stanford, California 94305

\section{ASSOCIATE EDITORS}
E. F. BECKENBACH
B. H. NeumanN
F. WOLF
K. YosHIDA

\section{SUPPORTING INSTITUTIONS}

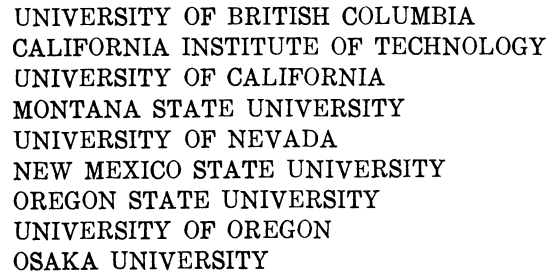

UNIVERSITY OF BRITISH COLUMBIA CALIFORNIA INSTITUTE OF TECHNOLOGY

UNIVERSITY OF CALIFORNIA

MONTANA STATE UNIVERSITY

UNIVERSITY OF NEVADA

NEW MEXICO STATE UNIVERSITY

OREGON STATE UNIVERSITY

UNIVERSITY OF OREGON

OSAKA UNIVERSITY

\author{
UNIVERSITY OF SOUTHERN CALIFORNIA \\ STANFORD UNIVERSITY \\ UNIVERSITY OF TOKYO \\ UNIVERSITY OF UTAH \\ WASHINGTON STATE UNIVERSITY \\ UNIVERSITY OF WASHINGTON \\ * * * \\ AMERICAN MATHEMATICAL SOCIETY \\ NAVAL WEAPONS CENTER
}

The Supporting Institutions listed above contribute to the cost of publication of this Journal, but they are not owners or publishers and have no responsibility for its content or policies.

Mathematical papers intended for publication in the Pacific Journal of Mathematics should be in typed form or offset-reproduced, (not dittoed), double spaced with large margins. Underline Greek letters in red, German in green, and script in blue. The first paragraph or two must be capable of being used separately as a synopsis of the entire paper. Items of the bibliography should not be cited there unless absolutely necessary, in which case they must be identified by author and Journal, rather than by item number. Manuscripts, in duplicate if possible, may be sent to any one of the four editors. Please classify according to the scheme of Math. Rev. Index to Vol. 39. All other communications to the editors should be addressed to the managing editor, or Elaine Barth, University of California, Los Angeles, California, 90024.

50 reprints are provided free for each article; additional copies may be obtained at cost in multiples of 50 .

The Pacific Journal of Mathematics is issued monthly as of January 1966. Regular subscription rate: $\$ 48.00$ a year (6 Vols., 12 issues). Special rate: $\$ 24.00$ a year to individual members of supporting institutions.

Subscriptions, orders for back numbers, and changes of address should be sent to Pacific Journal of Mathematics, 103 Highland Boulevard, Berkeley, California, 94708.

PUBLISHED BY PACIFIC JOURNAL OF MATHEMATICS, A NON-PROFIT CORPORATION

Printed at Kokusai Bunken Insatsusha (International Academic Printing Co., Ltd.), 270, 3-chome Totsuka-cho. Shinjuku-ku, Tokyo 160, Japan.

* C. R. DePrima California Institute of Technology, Pasadena, CA 91109, will replace J. Dugundji until August 1974.

Copyright (C) 1973 by

Pacific Journal of Mathematics

All Rights Reserved 


\section{Pacific Journal of Mathematics}

Vol. 48, No. $2 \quad$ April, 1973

Mir Maswood Ali, Content of the frustum of a simplex................

Mieczyslaw Altman, Contractors, approximate identities and factorization

in Banach algebras ................................ 323

Charles Francis Amelin, A numerical range for two linear operators ...... 335

John Robert Baxter and Rafael Van Severen Chacon, Nonlinear functionals

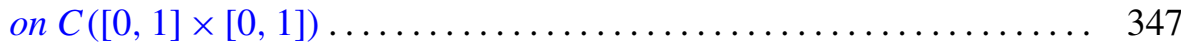

Stephen Dale Bronn, Cotorsion theories....................... 355

Peter A. Fowler, Capacity theory in Banach spaces............... 365

Jerome A. Goldstein, Groups of isometries on Orlicz spaces ........... 387

Kenneth R. Goodearl, Idealizers and nonsingular rings . ............ 395

Robert L. Griess, Jr., Automorphisms of extra special groups and

nonvanishing degree 2 cohomology ..................... 403

Paul M. Krajkiewicz, The Picard theorem for multianalytic functions . . . . 423

Peter A. McCoy, Value distribution of linear combinations of axisymmetric harmonic polynomials and their derivatives ...................

A. P. Morse and Donald Chesley Pfaff, Separative relations for

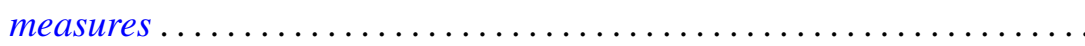

Albert David Polimeni, Groups in which $\operatorname{Aut}(G)$ is transitive on the

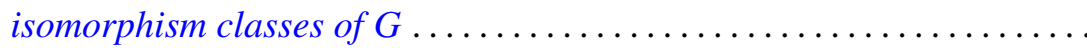

Aribindi Satyanarayan Rao, Matrix summability of a class of derived

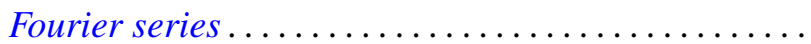

Thomas Jay Sanders, Shape groups and products

Ruth Silverman, Decomposition of plane convex sets. II. Sets associated

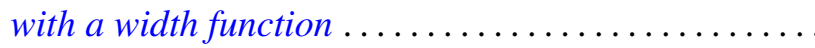

Richard Snay, Decompositions of $E^{3}$ into points and countably many flexible dendrites.............................

John Griggs Thompson, Nonsolvable finite groups all of whose local subgroups are solvable, IV ...

Robert E. Waterman, Invariant subspaces, similarity and isometric equivalence of certain commuting operators in $L_{p} \ldots$

James Chin-Sze Wong, An ergodic property of locally compact amenable

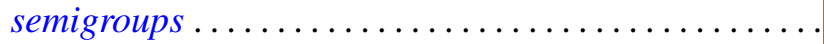

Julius Martin Zelmanowitz, Orders in simple Artinian rings are strongly equivalent to matrix rings ....................... 